\title{
Development of a Coreless Permanent Magnet Synchronous Motor for a Battery Electric Shell Eco Marathon Prototype Vehicle
}

https://doi.org/10.1515/eng-2018-0042

Received Jun 27, 2018; accepted Sep 05, 2018

\begin{abstract}
This paper describes the development of an inwheel Coreless Permanent Magnet Synchronous motor designed and built for the participation of the Aero@UBI team in Shell Eco-Marathon competition where a low power and highly efficient motor was needed. The design of the motor for this competition is presented and the adopted concepts explained. The conjunction of the concepts embedded in the design made this motor one of a kind. The use of Litz wire and a single wave winding turn allow the possibility to configure the motor's constant. The model used in the motor's design is presented. The motor was built, and the experimental tests data are given for the motor. The motor was tested with two different controllers and the results show the high efficiency of the presented motor.
\end{abstract}

Keywords: Motor; Coreless; Efficiency

\section{Introduction}

Shell Eco-marathon (SEM) is a global competition that challenges student teams around the world to design, build, test and drive ultra-energy-efficient vehicles. The present work describes the development of a Coreless Permanent Magnet Synchronous Motors (CPMSM) for the Aero@UBI01 SEM prototype. The CPMSM was found to be the most promising motor since in this type of electrical machine the iron hysteresis and induced currents are absent, thus offering the best scenario for reaching a top efficiency value. As disadvantages: CPMSMs have very small inductance compared to iron cored PMSM; have induced

\footnotetext{
^Corresponding Author: Miguel Ângelo Rodrigues Silvestre: CMast - Departamento de Ciências Aeroespaciais - Universidade da Beira Interior, Covilhã, Portugal; Email: mars@ubi.pt

Jorge M. G. Rebelo: Departamento de Ciências Aeroespaciais Universidade da Beira Interior, Covilhã, Portugal
}

currents in the coils copper and may require more copper and magnet weight to reach the same motor constant, $K v$, if not design properly.

\section{Background}

Concerning the state of the art of the CPMSM: Caricchi et al. [1] describe the design, construction and experimental testing of a CPMSM to use in a dual-power city car. The efficiency curve with rotation speed was remarkably flat near a maximum of $97 \%$. Later, in 1998, a solar vehicle in-wheel three-phase CPMSM was developed by CSIRO [2]. The motor uses a Hallback magnet array to maximize the motor torque constant and Litz wire to minimize the induced current losses in the copper coils. The final design weights 6 $\mathrm{kg}$ with $4.8 \mathrm{~kg}$ of rare earth Neodymium magnets, reaching an estimated efficiency is $97.8 \%$. The motor power is $1800 \mathrm{~W}$ at $1060 \mathrm{rpm}$. This motor has been made commercially available as a kit by Marand [3] for around 10,000 euros. A variant with a simple magnet array is also available at a lower cost but lower peak efficiency. These two versions are being used by various solar vehicle teams all over the world. Nevertheless, the CSIRO motor is two orders of magnitude too powerful for a SEM prototype vehicle. In 2010 Colton [4] presents simple, low-cost design and prototyping methods for custom brushless permanent magnet synchronous motors. Different modelling strategies are explored to design the motor's prototypes. It is shown that using a first-order motor model analysis, the motor's performance can be predicted with good accuracy. Three casestudy motors were used to develop, illustrate and validate the rapid prototyping methods for brushless motors, proving that these are useful in the fabrication and development of such motors. One of the three case study was an axial flux CPMSM that showed a disappointing efficiency. This was attributed to not having considered the induced current losses in the copper coils. But no Litz wire was used for that motor. Recently, LaunchPoint Technologies, Inc [5] presented a high efficiency CPMSM. It is an axial flux con- 
figuration with a dual permanent magnet Halbach array, and the reported efficiency is $95 \%$. This motor is claimed to have the higher power density on the market, at 8.2 $\mathrm{kW} / \mathrm{kg}$. Students from the Norwegian University of Science and Technology have been working on Axial Flux CPMSM for their participations in Shell Eco-marathon. Their work is described in $[6,7]$. They have estimated that the motor would achieve $97,2 \%$ efficiency, with a mass of $6,24 \mathrm{~kg}$ but report that it was measured reaching an efficiency of $68 \%$. This disappointing value was attributed to the difficulties found in the production of the rotor and the wiring. Finally, Buøy [8] built another version of the motor based in the Nasrin design but using different production methods. A measured efficiency of $96.3 \%$ is reported. In 2014, Batzel et al. [9] starting from requirements and drive constraints, such as power, speed, voltage and diameter describe the designed and testing of an axial flux CPMSM. A Halbach array was used to concentrate the magnetic flux on the air gap and allowing the absence of the back iron for the rotor magnets, thus reducing the weight of the motor. The machine efficiency was determined by measuring de phase voltages and currents input and measuring the torque and speed of the shaft output. The total weight of the motor was $4.8 \mathrm{~kg}$ a power of about $1 \mathrm{~kW}$ and an efficiency over $90 \%$ is reported for a wide the range of operation.

\section{Methodology}

\subsection{Conceptual Design}

It was decided that the use of a direct-drive motor is desirable because of the absence of reduction and transmission losses in the vehicle. At the same time, results in low vehicle cost and system volume and in higher reliability. In consideration of the high-torque operation required at relatively low speeds, permanent magnet (PM) motors are best fit to the direct-drive application [10]. It was decided to develop the motor from the concept previously used with success in solar electric car competitions, the CSIRO motor [2]. It is an axial flux permanent magnet coreless synchronous motor. In the conception of the Aero@UBI01 car, in the initial stage, a model to predict the car performance was developed with the most significant parameters regarding to the car performance. With this model, the motor power requirements were determined. SEM race rules dictate that the prototype category vehicles must perform with a mean speed of about $25 \mathrm{~km} / \mathrm{h}$ for the race.

In our case, it was realized that, in the same way the electric current ripple increases the Joule energy losses in the motor for the same mean current value, an airspeed ripple during the race increases the drag losses for the same mean value of $25 \mathrm{~km} / \mathrm{h}$. So, considering the absence of atmospheric wind during the race and that the race track in Rotterdam, Netherland, is mostly flat, it was decided that the driver must maintain the a velocity above but close to $25 \mathrm{~km} / \mathrm{h}(7.03 \mathrm{~m} / \mathrm{s}$ was considered) and, thus, the motor is designed for maximum efficiency at that continuous power and torque design point condition with the possibility of having moments during the race where higher power or torque is needed. E.g., overtaking another vehicle in the racing circuit. Considering the wheel diameter of $0.478 \mathrm{~m}$, the angular speed of the motor will be 29.4 $\mathrm{rad} / \mathrm{s}$. Regarding the motor efficiency goal, the parametric study of the car prototype performance indicated that the motor could be made $3 \mathrm{~kg}$ heavier if its efficiency would rise $1 \%$.

Table 1: Motor requirements

\begin{tabular}{lc}
\hline Requirement & Value \\
\hline Continuous output shaft power (cruise) & $15 \mathrm{~W}$ \\
Peak shaft power & $400 \mathrm{~W}$ \\
Rotational speed at $25.3 \mathrm{~km} / \mathrm{h}(7.03$ & $29.4 \mathrm{rad} / \mathrm{s}$ \\
$\mathrm{m} / \mathrm{s})$ & \\
Continuous torque (cruise) & $0.510 \mathrm{Nm}$ \\
Peake torque & $13.605 \mathrm{Nm}$ \\
Maximum outside diameter & $370 \mathrm{~mm}$ \\
Maximum axial length & $70 \mathrm{~mm}$ \\
\hline
\end{tabular}

The conceptual design of the motor results from the implementation of multiple ideas and concepts, to meet the vehicle requirements and from previous works mentioned in Section 2, in order to achieve the higher efficiency. Here is a list of the implemented concepts: Axial flux rotor configuration - is suitable to fit in the vehicle's wheel; Steel back rotors - the magnetic flux between rotor magnets is closed by ferromagnetic steel plates that act also as a structural rotor support to hold the magnets; Litz wire use - to minimize eddy current losses occurring in the stator copper, the use of Litz wire was mandatory. The copper wire eddy current losses are proportional to the fourth power of the wire diameter [11]. From the search for a Litz cable provider, the commercially available specifications and the stator geometry and dimensions led to the choice of the 10x18 individually insulated wires of $0.1 \mathrm{~mm}$ diameter; Configurable motor - the use of a single wave winding turn from a cable of 10 sets of 18 individually insulated wires allows to configure the motor wind- 

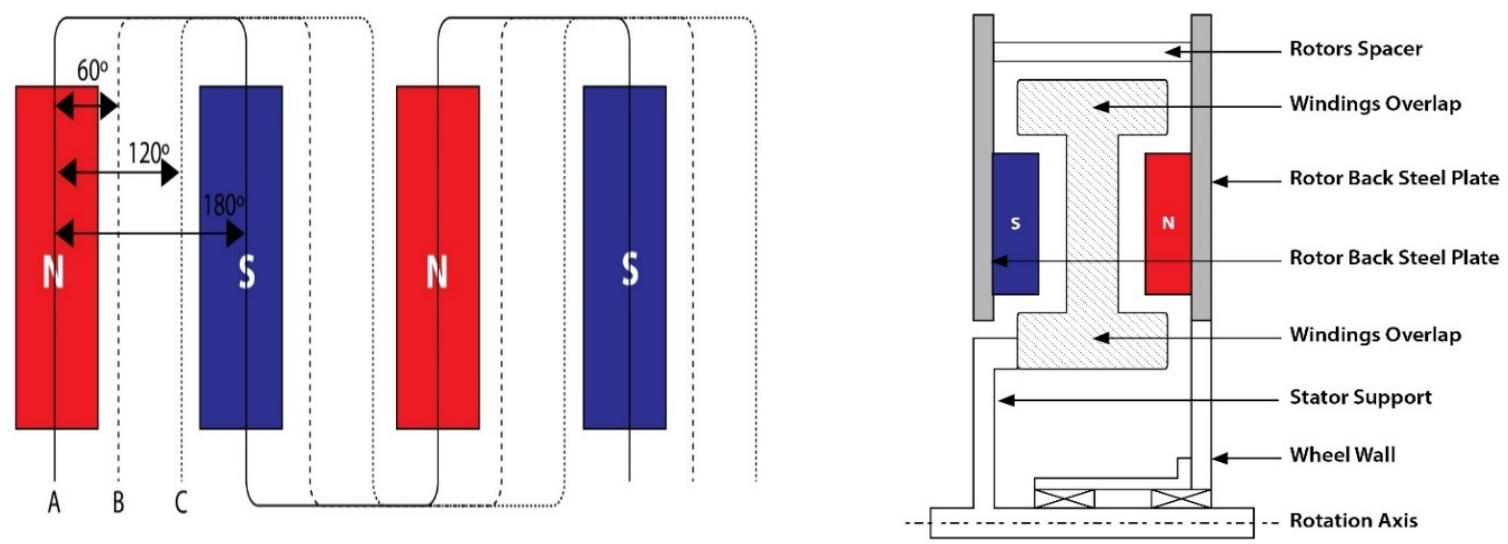

Figure 1: Wave winding concept (left). Motor section concept (right)

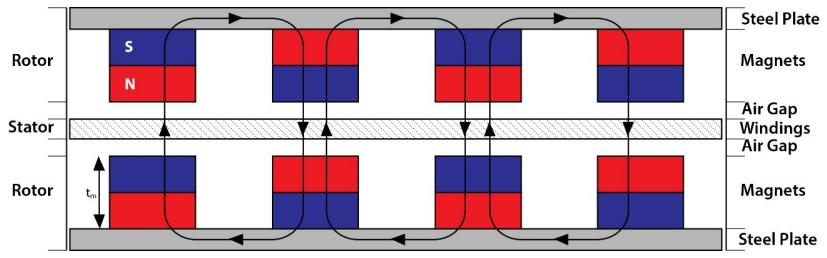

Figure 2: Motor axial flux coreless motor concept

ing with multiple winding options. From the basic configuration of a single turn with 180 parallel wires to a 10 turn coil of 18 parallel wires. In this manner, the motor constant is, in fact, adjustable to a different application of the motor; Three-phase - because it is the minimum phase number allowing constant torque which is crucial when starting the vehicle; Minimized stator thickness between opposing magnet poles faces - due to the coreless concept magnet flux dispersion, the thinner the stator the better. This was achieved by adopting wave winding and using a single turn per phase for the motor. So, the motor stator is as thin as a single squeezed cable of $10 \times 18$ isolated wires $(\sim 3 \mathrm{~mm})$. The three phases do not overlap in the stator between the magnets, they overlap in the radial inner and outer edges of the stator, outside the inter faces region existing between opposing magnets; Wave winding - wave winding was adopted because allows the smaller stator thickness (see Figure 1 (right)); Special endturns inter-phases overlapping - the overlapping of the phases windings is limited to radial inner and outer edges of the stator, contrary to the CSIRO in-wheel motor where they overlap in between the opposing magnets faces [2]; N52 NdFeB magnets - rare earth magnets are becoming standard in PM motors. They allow greater magnetic flux in the stator coils per magnet unit mass. Thus, reducing the coils turns reduces the length of coil wire, therefore smaller phase resistance, size and weight to reach a given motor constant, $K_{t}$, and efficiency. The drawback of these higher specification limit magnets is the operating temperature limit $\left(80^{\circ} \mathrm{C}\right)$. But, for a high efficiency and small power motor with little restrictions in size and weight, the temperature build up in the motor is not an issue; Low cost magnets per unit mass - the mass of magnets relates inversely with the size of required coils to reach a given motor constant, $K_{t}$, and efficiency. So, to make use of the least cost restricted mass of magnets possible, the commercially available NdFeB magnets with lowest price per unit mass were identified. For the small number of magnets necessary for the motor prototype, the minimum price that was found was $51 € / \mathrm{kg}$. Given all the geometrical constrains and number of pole pairs optimization, the chosen magnets were at a price tag of $60 € / \mathrm{kg}$; Gap between magnets - the placement of magnets was such that there was a gap between them approximately equal to the magnet thickness because it was believed that such arrangement would result in a BEMF closer to sinusoidal. Adjustable air gap - although the air gap is, generally, minimized, the option to make it adjustable allows to fine tune the motor constant to the actual motor use. The final conceptual design of the developed motor is shown in Figure 1 and Figure 2.

\subsection{Preliminary Design}

The motor design variables were: Voltage of the DC bus, $U_{D C}$; Shaft Power, Pc; angular speed, $\omega$; Motor Efficiency, $\eta_{c}$; mean radius at magnets center position, $r$; magnet poles number, p; flux intensity of the magnets, $B_{m a g}$; mag- 
net thickness tm, Stator filling factor, FF; magnet pole length, $\mathrm{L}$; magnet pole width, $\mathrm{W}$ and the airgap thickness of $2 \mathrm{~mm}$. So, in the first design iteration, all these variables values were assigned. In the case of $U_{D C}$, it had to be a multiple of 3.7V because the SEM competition rules mandate the use of a lithium-ion battery. In the first design iteration, the value was set to $7.4 \mathrm{~V}$ but the final design point uses $15 \mathrm{~V}$ and the actual vehicle's battery uses $22.2 \mathrm{~V}$ to reach a top speed sufficiently above the design speed. Table 1 shows the values that were used for Pc, 15W, for $\omega, 29.4 \mathrm{rad} / \mathrm{s}$ and the maximum radius of the motor, $340 \mathrm{~mm} / 2=0.17 \mathrm{~m}$.

The main constrain for the motor development was the motor cost and the main cost share was found to be for the magnets. So, these were chosen for their low cost; their geometric suitability to the in-wheel motor, and peak magnetic flux density rating. The adopted magnets were N52 flux rated NdFeB magnets with $\mathrm{L}=0.030 \mathrm{~m}$; $\mathrm{W}=0.012$ and $\mathrm{tm}=0.012 \mathrm{~m}$ costing $60 € / \mathrm{kg}$. So, the mean radius of the magnets was set at $0.15 \mathrm{~m}(0.17-0.03 / 2=0.155$ subtracted of a $5 \mathrm{~mm}$ radial margin). The magnetic flux density of these N52 specified magnets reaches a $B_{m a g}=1.48 \mathrm{~T}$. A stator filling factor of $\mathrm{FF}=0.3$ was assumed. The major unknowns were the number of magnet poles and the efficiency that the motor could be designed for. So, during the design iterations, $\mathrm{p}$ was varied in the range of 32 to 40 and $\eta_{c}$ from 0.96 to 0.99 .

To model the motor, the first step is to obtain the available AC tension, $U_{A B_{r m s}}$ from the $\mathrm{U}$ (1).

$$
U_{A B_{r m s}}=\frac{\sqrt{3}}{2 \sqrt{2}} U
$$

The motor electrical power is obtained from the shaft power, using the design point motor efficiency (2).

$$
P_{e}=\frac{P_{c}}{\eta_{c}}
$$

From the motor electrical power, the motor current is obtained (3).

$$
I_{r m s}=\frac{P_{e}}{U}
$$

The motor phase current is also obtained from the motor electrical power, (4).

$$
I_{A B C r m s}=\frac{1}{\sqrt{3}} \frac{P_{c e}}{U_{A B_{r m s}}}
$$

Knowing motor phase current, the motor total Joule power loss is calculated with Equation (5) assuming half the losses will occur due to internal flow drag (windage loss) and eddy-currents in the copper. So, the windage power loss is equal to the Joule power loss.

$$
3 R I^{2}=\frac{\left(P_{c e}-P_{c}\right)}{2}
$$

The phase winding resistance is found from the total Joule power loss by Equation (6).

$$
R=\frac{R I^{2}}{3 I_{A B C r m s}}
$$

The motor resistance voltage drop, which is the required electromotive force to reach the motor phase current is calculated from Equation 7).

$$
U_{\text {emf }}=3 R I_{A B C_{r m s}}
$$

The required motor effective back electromotive force, $U_{\text {bemfrms }_{r}}$, is obtained from Equation (8).

$$
U_{b e m f_{r m s}}=U-U_{e m f}
$$

The motor constant $K_{t}$ is now obtained from Equation (9).

$$
K_{t}=\frac{U_{b e m f_{r m s}}}{\omega}
$$

The angle corresponding to half electric revolution is calculated from the motor pole pair number $p$ from Equation (10).

$$
\alpha=\frac{2 \pi}{p}
$$

The duration of the coil motion from one magnet to the next is calculated from Equation (11).

$$
t_{\text {mag }}=\frac{\alpha}{\omega}
$$

The motor stator mean perimeter is given by Equation (12).

$$
p_{e r}=2 \pi r
$$

The stator outer perimeter is given by Equation (13).

$$
p_{\text {er }}=2 \pi r\left[r+\frac{L}{2}+0.005\right]
$$

The stator inner perimeter is given by Equation (14).

$$
p_{e r_{i n n}}=2 \pi r\left[r-\frac{L}{2}-0.005\right]
$$

The distance between opposing magnets faces, for the air gap in each face of the stator plus the stator itself with thickness, $t_{s}$, (see Figure 2) is determined by Equation (15).

$$
g=t_{s}+4
$$

Regarding the mean flux density at the stator, it was considered to be $90 \%$ of the peak magnet flux density and proportional to the total thickness of the magnets surrounding the stator coil, $2 t$ (see Figure 2) is determined by Equation (16).

$$
B_{\text {coil }}=0.9 B_{\text {mag }} \frac{2 t}{(g+2 t)}
$$


The wave winding coil area subjected to the magnetic flux is calculated according to Equation (17).

$$
A=L W p
$$

The magnetic flux is calculated from Equation (18).

$$
\phi=A B
$$

The pole width available at the mean stator perimeter is $p_{e r} / 2$. The desired magnet width was checked as $p_{e r} / 4$. It should be close to $W$ such that the gap between successive rotor magnets was close to the value of $W$. It could never approach $2 W$ or the magnets could not be fitted in the rotor.

The flux gradient in the stator coil is considered as $\frac{2 \phi}{t_{m a g}}$. A maximum single coil voltage drop was calculated by Equation (19).

$$
R I=1.25 R I_{A B C} r m s
$$

So, the required maximum phase voltage is given by Equation (20).

$$
U_{A B C}=\frac{U_{A B_{m s}}}{\sqrt{3}}-R I
$$

The required turns per coil is obtained from Equation (21). The actual design point had to correspond to a finite $N$ number.

$$
N=\frac{U_{A B C}}{\frac{2 \phi}{t_{\text {mag }}}}
$$

The length of coil wire per turn per coil is obtained from Equation (22).

$$
l p=2 p(L+0.01)+0.6 p_{e_{\text {out }}}+0.6 p_{e r_{\text {inn }}}
$$

The total wire length per coil is obtained from Equation (23).

$$
l_{N}=N\left(l_{p}+1\right)
$$

The minimum copper coil wire section area was calculated from Equation (24) considering a copper wire resistivity at $40^{\circ} \mathrm{C}$ of $2.06 \times 10^{-8} \Omega \mathrm{m}$.

$$
A_{N}=2.06128 \times 10^{-8} \frac{l_{N}}{R}
$$

The corresponding diameter was calculated from Equation (25).

$$
d_{\text {wire }}=2 \sqrt{\frac{A_{N}}{\pi}}
$$

The minimum copper volume per phase was calculated from Equation (26).

$$
V_{\text {wire }}=A_{N} l_{N}
$$

The motor stator copper mass for the required copper volume per phase was calculated by Equation (27) considering a copper density of $8930 \mathrm{~kg} / \mathrm{m}^{3}$.

$$
m_{\text {wire }}=8930 V_{\text {wire }}
$$

The stator disk area perpendicular to the axial axis was calculated from Equation (28).

$$
A_{S}=2 \pi\left[\left(r+\frac{L}{2}+0,005\right)^{2}-\left(r-\frac{L}{2}+0,005\right)^{2}\right]
$$

The required stator thickness was calculated considering the filling factor from Equation (29).

$$
t_{s}=\frac{3 V_{\text {wire }}}{A_{S} F_{F}}
$$

The required motor magnets mass was calculated, considering the filling factor from Equation (30) and considering a NdFeB magnet density of $7500 \mathrm{~kg} / \mathrm{m}^{3}$.

$$
m_{\text {mag }}=2 p\left(7500 W L t_{m}\right)
$$

In order to decide what pole count, $p$, would be used in the motor, a parametric study was performed to see how much mass the motor would have due to the desired design efficiency. So, calculations where performed to determine the copper mass in the stator windings due to the adoption of different pole count in function of the design point efficiency of the motor. The study was performed in a range of 32 to 40 poles. The magnet mass for 32 poles was estimated at $2.1 \mathrm{~kg}$ and for 40 poles a value of $2.6 \mathrm{~kg}$ was expected. The results are presented in Figure 3. The results for the total mass of rotor magnets plus stator copper are presented in Figure 4. The adopted design was considered a good compromise between magnet mass, the corresponding cost and the value of efficiency that corresponded. A higher magnet poles number would increase even further the total magnet mass and, thus, motor cost.

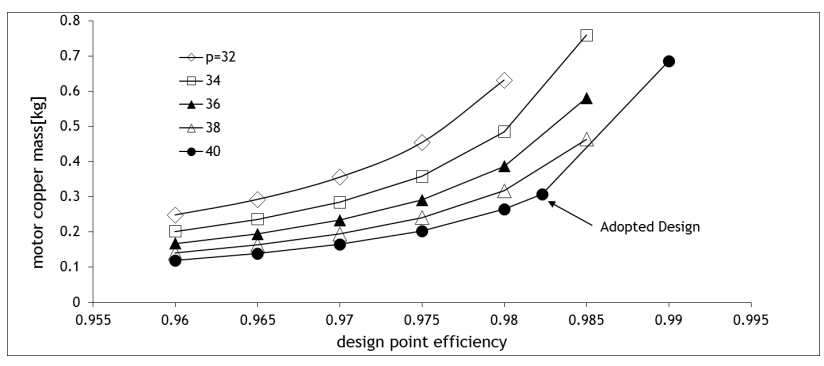

Figure 3: Motor stator copper mass due to pole count in function of design point efficiency 


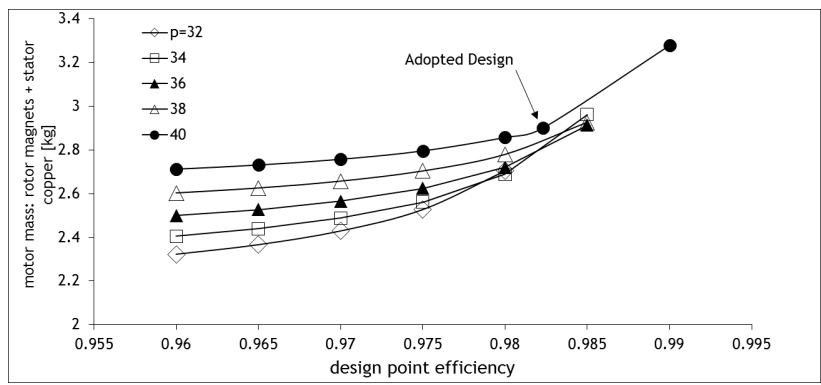

Figure 4: Motor mass versus design point efficiency

Table 2: Design Point Motor Parameters

\begin{tabular}{lc}
\hline Geometrical Parameters & Value \\
\hline Outer diameter & $0.370 \mathrm{~m}$ \\
Inner diameter & $0.260 \mathrm{~m}$ \\
Axial lenght of the motor & $0.070 \mathrm{~m}$ \\
Diameter of the motor & $0.370 \mathrm{~m}$ \\
Number of turns & 2 \\
Fill factor & 0.3 \\
Troque constant & $0.504 \mathrm{Nm} / \mathrm{A}$ \\
Air gap & $0.007 \mathrm{~m}$ \\
\hline Electrical Losses & Value \\
\hline Nominal motor current & $1.03 \mathrm{~A}$ \\
Resistance & $0.048 \Omega$ \\
Copper loss & $0.066 \mathrm{~W}$ \\
Magnetic flux density & $1.029 \mathrm{~T}$ \\
Windage loss & $0.0676 \mathrm{~W}$ \\
\hline Weight & Value \\
\hline Magnet mass & $2.59 \mathrm{~kg}$ \\
Copper mass & $0.31 \mathrm{~kg}$ \\
\hline
\end{tabular}

\subsection{Detailed Design}

From the preliminary design study presented in Section 3.2 and implemeting the concepts from the conceptual design (Section 3.1) the motor was designed in CATIA V5 CAD software. Table 2 shows the parameters of the adopted design.

The motor design is based on the two principal parts of a motor: the rotors and the stator. The rotors plates are separated by 20 screws that resist to the magnetic attraction between the rotors magnets, this screws are also used to align the rotors in the assembly and dissasembly of the motor and to ajust the air gap. The stator is secured in position by three screws that allow adjustment of its plane in relation to the rotors in order to correct any misalignment. A CAD rendering of the motor in an exploded view is shown in Figure 5 (left). The finished motor is shown in Figure 5 (right).

\subsection{Motor Testing}

By comparing the predicted BEMF at the design point with the BEMF from the motor, it was possible to evaluate if the developed motor behaved like the predicted design. By measuring the two terminals of one phase with an oscilloscope it was possible observe the shape and amplitude of the BEMF while the motor was rotated by hand.

The measurement of the motor mechanical losses was done by measuring its kinetic energy drop per unit time when freewheeling near the design angular speed of 277 rpm. The experiment starts by accelerating the motor to about $285 \mathrm{rpm}$ and measure the time it takes to decelerate to $270 \mathrm{rpm}$. Knowing the kinetic energy of the motor rotor at two different angular speeds and the time that it takes to deaccelerate between them, the total freewheeling power loss is determined. To determine the kinetic energy at a given angular speed, the moment of inertia of the motor also had to be determined. So, it was measured too. The motor was mounted with the terminals of one phase connected to the oscilloscope to acquire its frequency (thus, angular speed). A falling mass, $m$, of known value was hanged by a cable wound in the periphery of the rotor to accelerate the motor during a known vertical distance drop. The final motor's angular speed was measured. Since the energy supplied by the falling mass is known, the motor rotor's moment of inertia is related to the measured motor angular speed by Equation (31). The results are presented in Section 4.

$$
I=\frac{2\left[m g h-\frac{1}{2} m(\omega r)^{2}\right]}{\omega^{2}}
$$

The motor and an in-house developed controller were tested together, as a system, to evaluate its performance. The tests were repeated with a commercially available controller from Texas Instruments (TI C2000 + DRV8301). For these tests, the motor and controller were mounted on a test rig like they are installed on the Aero@UBI car prototype. For these tests, the energy was supplied from a regulated bench power supply that shows the voltage and current sourced to the motor and controller. The motor speed was calculated from the frequency of the BEMF signal monitored on the oscilloscope. A test with no load applied to the motor was done to compare the power needed to keep the motor spinning at $277 \mathrm{rpm}$ with the motor's previously measured losses. In this condition, the energy consumed is only used to keep the motor running. The next step was to apply a load to the motor. This load should represent the torque applied on the motor when it is running the SEM car prototype on the track (Table 2). Figure 6 shows the test rig used in this loaded motor system testing. 


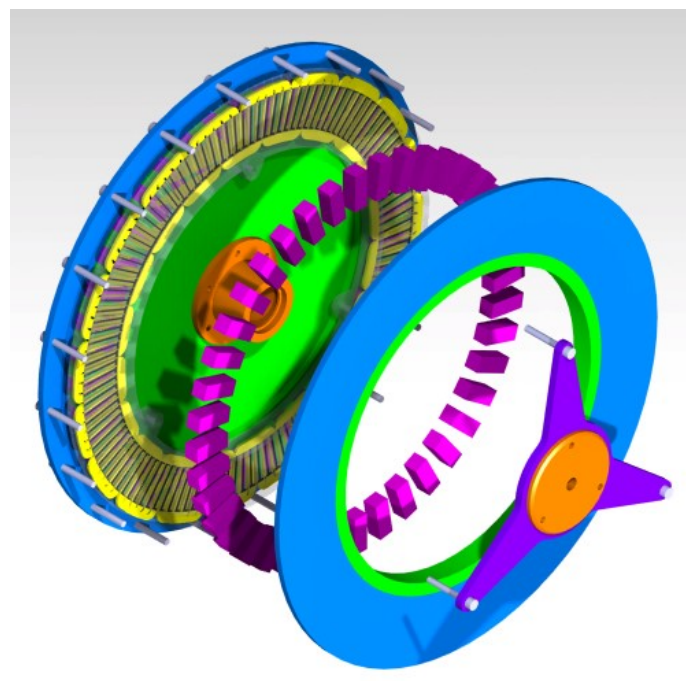

Figure 5: Final motor design (left). Final product (right).

The torque applied to the motor was accomplished by using to weights hanging in the ends of a leather strap. The leather strap, in contact with the rotor, creates friction that is proportional to the $m_{2}$ weight. The weight $m_{1}$ must be higher than $m_{2}$ plus the force that the motor performs on the strap.

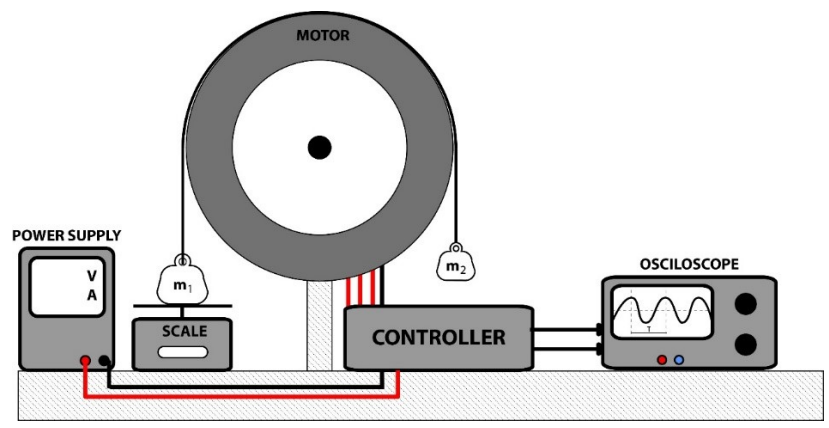

Figure 6: Schematic of the test bench used for load measurements

\section{Results}

Figure 7 (left) illustrates the measured voltage waveform compared to a sinusoidal waveform. The measured motor BEMF shows a significant difference against the desired sinusoidal wave, this is attributed to the difference between the magnet width $(12 \mathrm{~mm})$ and the and wave coil width around the magnet $(23.5 \mathrm{~mm})$, making the linearity of the BEMF crossing the zero voltage disappear. Once the magnet flux is inside the coil, it does change until the magnet

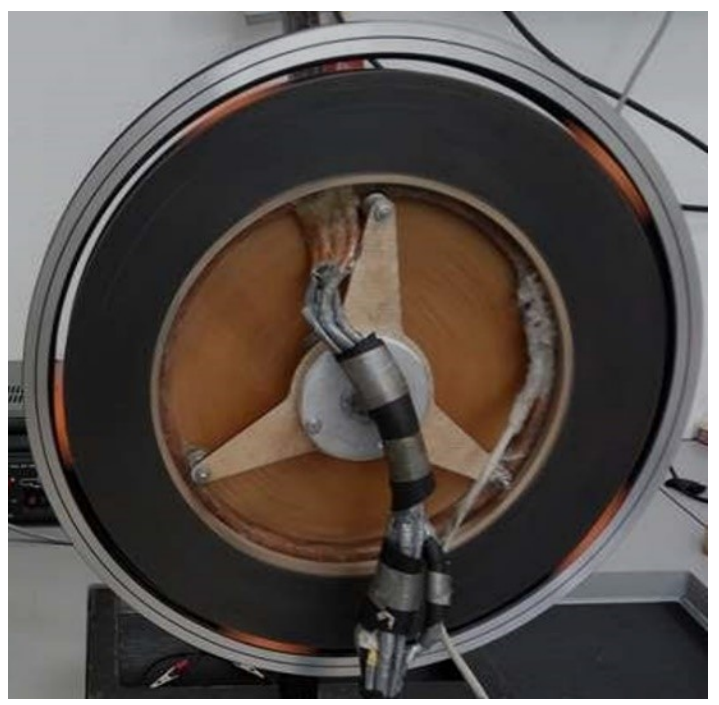

it reaches the other end of the coil, this time gap reflects in the drop of the BEMF gradient.

The measured moment of inertia of the motor rotor is $0.240 \mathrm{kgm}^{2}$. Using the measured moment of inertia and the measured time to decelerate from $285 \mathrm{rpm}$ to $270 \mathrm{rpm}$, the motor's mechanical power loss near the design point was obtained with an average result of $2.558 \mathrm{~W}$.

The motor rotation speed was kept around $277 \mathrm{rpm}$ in the motor controller system testing. The total power required to spin the motor was measured at a mean value of $5.98 \mathrm{~W}$. Note that in this value the power consumption of the controller and motor mechanical losses are included. Additionally, the motor Joule losses are present. The CPMSM has low inductance, at the same time, it must have the lowest possible resistance because the Joule losses are directly proportional to the resistance. It is, thus, characterized by low, $\mathrm{R}$ and $\mathrm{L}$ therefore, it is prone to large current ripple. Therefore, the efficiency of the motor running in the vehicle depends strongly from the controller performance on matching the motor BEMF to minimize the Joule losses and make use of the driving current to generate motor torque.

Figure 7 (right) shows the experimental data corresponding to the motor-controller system tested in the test rig described in Section 3.4. The motor rotation speed and load was kept close to the design $277 \mathrm{rpm}$ and $0.510 \mathrm{Nm}$, respectively. From Figure 7 (right) were the tests results of the motor-controller system efficiency are presented. The designed motor-controller system (has an efficiency of $83 \%$ through the design point). The data corresponding to the use of Texas Instruments DRV sinusoidal FOC controller are also presented for comparison. When using the TI con- 

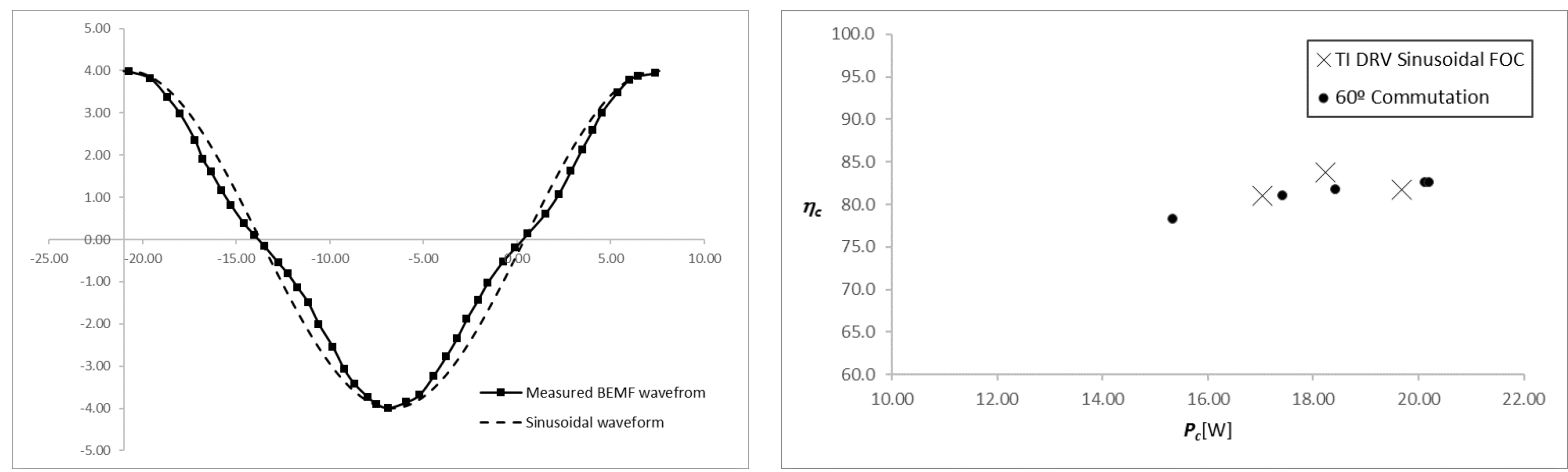

Figure 7: Measured voltage waveform vs sinusoidal waveform (left). Motor-Controller system efficiency experimental results with TI DRV controller and the in-house developed $60^{\circ}$ commutation controller (right).

troller, 90mH choke inductors are connected in series with the motor phase terminals to limit the current ripple and improve the TI controller sensing. It is seen that the peak efficiency of the developed, $60^{\circ}$ commutation controller is quite near the efficiency of the state of the art commercial sinusoidal field-oriented controller.

\section{Concluding Remarks}

The design of a CPMSM is presented. The concepts embedded in the design are thoroughly described. In the SEM 2015 event in Rotterdam, with a flat track, the result of the Aero@UBI01 prototype was $331 \mathrm{~km} / \mathrm{kWh}$, corresponding to the 19th place in the battery electric prototypes category out of 33 vehicles that achieved a result on the track. In 2017, the vehicle's body and chassis were changed and the result improved to $372 \mathrm{~km} / \mathrm{kWh}$. Corresponding to the 11th place in 39 battery electric vehicle prototypes participating in SEM Europe in London despite that the track has a steep 5\% uphill incline that was not favorable to the current motor controller system. It is noteworthy to mention that all teams except ours and University of Applied Sciences Offenburg team were using very similar versions of DC brushed MAXON motors of about $200 \mathrm{~W}$ power. The German team got in the 8th place and uses an in-wheel motor that is CPMSM.

As future work, the developed motor will be characterized regarding the high power working limit and respective efficiency. Significant weight reduction of the current motor can be achieved if the rotors steel plates are replaced by a carbon fiber composite material.

Acknowledgement: This work has been supported by the project Centro-01-0145-FEDER-000017 - EMaDeS - Energy, Materials and Sustainable Development, co-financed by the Portugal 2020 Program (PT 2020), within the Regional Operational Program of the Center (CENTRO 2020) and the European Union through the European Regional Development Fund (ERDF).

The authors wish to thank the opportunity and financial support that permitted to carry on this project.

\section{References}

[1] F. Caricchi, F. Crescimbini, A. Di Napoli, and M. Marcheggiani, Prototype of electric vehicle drive with twin water-cooled wheel direct drive motors, PESC Record - IEEE Annual Power Electronics Specialists Conference, 1996, vol. 2. pp. 1926-1932.

[2] H. C. Lovatt, V. S. Ramsden, and B. C. Mecrow, Design of an in-wheel motor for a solar-powered electric vehicle, IEE Proc. Electr. Power Appl., 1998, vol. 145, no. 5, p. 402.

[3] J. Brown, High Efficiency Permanent Magnet Motor, Marand Precision Engineering, 2010, http://www.ata.org.au/wp-content/ uploads/marand_high_efficiency_motor.pdf.

[4] S. W. Colton, Design and prototyping methods for brushless motors and motor control (MSc thesis),2010, Massachusetts Institute of Technology.

[5] M. Ricci, "LaunchPoint Technologies Announces New High Efficiency, High Power Density, Halbach Array Electric Motor," 2009, [Online], Available: http://www.prweb.com/releases/ high-power-density/electric-motor/prweb2870024.htm. [Accessed: 26-Jun-2016].

[6] F. V. Endresen, Electric Motor Development for Shell (MSc thesis), 2012 Norwegian University of Science and Technology.

[7] L. Nasrin, Improved Version of Energy Efficient Motor for Shell Eco Marathon: Half Weight with Higher Efficiency (MSc thesis), 2011, Norwegian University of Science and Technology.

[8] J. O. Buøy, Development of high efficiency Axial Flux Motor for Shell Eco-marathon (MSc thesis), 2013, Norwegian University of Science and Technology.

[9] T. D. Batzel, A. M. Skraba, and R. D. Massi, Design and Test of an Ironless Axial Flux Permanent Magnet Machine using Halbach Array, IAJC-ISAM Jt. Int. Conf., 2014, p. 2.

[10] Y. Jung, T. Long, J. N. Pe, and C. L. Me, Unique Axial Flux Motor Design Delivers Superior Torque Density, 2008, pp. 1-6. 
[11] R. J. Wang, M. J. Kamper, K. Van Der Westhuizen, and J. F. Gieras, "Optimal design of a coreless stator axial flux permanentmagnet generator, IEEE Trans. Magn., 2005, vol. 41, pp. 55-64. 